\title{
Relationship Between the Fluoride Concentration of the Fluoride-releasing Elastomers and the Acquired Acid Resistance of Human Enamel in vitro
}

\author{
Xing Yan WANG, Koji MIYAZAKI ${ }^{1}$ and Wataru MOTOKAWA ${ }^{2}$ \\ Graduate School, \\ ${ }^{1}$ Department of Dental Engineering (Bioengineering Section), \\ ${ }^{2}$ Department of Oral Growth \& Development, \\ Fukuoka Dental College \\ 2-15-1 Tamura, Sawara-ku, Fukuoka 814-0193, Japan
}

Received January 10, 2003/Accepted March 28, 2003

\begin{abstract}
The objective of the study was to evaluate the relationship between the fluoride concentration of the fluoride-releasing elastomers and the acquired acid resistance of human enamel. Four kinds of fluoride concentration of the experimental fluoride-releasing elastomers were $1.25,2.5,3.75$ and $5.0 \mathrm{wt} \%$. An enamel block was cut into two smaller enamel blocks, one of which was set with an elastomer, the other as a control not set with elastomer. A plastic block that had the same shape as the small enamel block was also set with elastomer. Fluoride release and acid resistance tests were carried out. The mineral loss of the demineralized enamel was measured by microradiography. The results showed that the fluoride-releasing ability significantly increased with the increase of fluoride concentration in the elastomer $(p<0.05)$. The acid resistance of the enamel appeared to be enhanced greatly, however, its change was not proportional to the fluoride concentration in the elastomers.
\end{abstract}

Key words: Fluoride-releasing elastomer, Fluoride concentration, Acquired acid resistance

\section{INTRODUCTION}

To prevent enamel demineralization in orthodontics, fluoride-releasing elastomers have been developed and studied. In the 1990's, fluoride-releasing elastomeric chains (Fluor-I-chain) and elastomeric ligature ties (Fluor-I-ties) were developed in the U.S.A. Storie et al. ${ }^{1)}$ evaluated the fluoride-releasing ability and some mechanical characteristics of Fluor-I-chain. Banks et al. ${ }^{2}$ undertook a clinical study on fluoridereleasing Fluor-I-Chain and Fluor-I-Ties. Although the elastomers showed some fluoride-releasing ability and reduced enamel decalcification by $49 \%$ clinically, the mechanical properties of the elastomers were sacrificed because of impregnation of fluoride, which severely limited their clinical use.

It is well known that with the increase of the amount of fluoride dispersed in the elastomer the mechanical properties will inevitably become worse. In 2000, in order to develop a new fluoride-releasing elastomer which was more suitable for clinical use, Itoh et al. ${ }^{3)}$ chose two kinds of polyurethane elastomers (E580 and E590), which had excellent mechanical properties, prepared fluoride-releasing elastomers with $\mathrm{SnF}_{2}$ $1.25-5.0 \mathrm{wt} \%$ and evaluated the fluoride-releasing ability and some mechanical 
characteristics.

In 2001 Wang et $a$. $^{4)}$ assessed the effect of elastomers on acid resistance of human enamel in vitro. It was found that elastomers containing 2.5 or $5.0 \mathrm{wt} \%$ tin fluoride $\left(\mathrm{SnF}_{2}\right)$ enhanced the acid resistance of enamel by over $50 \%$. Although the fluoride concentration of the two kinds of elastomers differed, the acquired acid resistance rate $(A R)$ of human enamel affected by the elastomers showed no significant difference. To further clarify the relationship between the fluoride concentration of the fluoride-releasing elastomers and AR, elastomers with four kinds of fluoride concentration $(1.25,2.5,3.75$ and $5.0 \mathrm{wt} \%)$ were prepared. Their fluoride-releasing ability and acid resistance of the enamel affected by the elastomers were investigated in vitro.

\section{MATERIALS AND METHODS}

\section{Preparation of the experimental fluoride-releasing elastomers}

Proportional quantities of polyurethane elastomer (E580, Nihon Miractoran, Osaka, Japan) and tin fluoride (G: 10-80 $\mu \mathrm{m}$, Kanto Chem. Co., Tokyo, Japan) were kneaded using a hot kneading machine $\left(160^{\circ} \mathrm{C}\right)$ for 5 minutes and pressed into $0.5 \mathrm{~mm}$-thick sheets at a laboratory in Nihon Miractoran (Atsugi, Japan). The concentrations of tin fluoride in the elastomeric sheets were respectively $1.25,2.5,3.75$ or $5.0 \mathrm{wt} \%$. The ring-shaped experimental fluoride-releasing elastomers were made from the sheets using a hot metal mold $\left(160^{\circ} \mathrm{C}\right)$. The size of the elastomer was approximately similar to ALASIK ${ }^{\mathrm{TM}}$ Separator Modules S2 (inner diameter $2.4 \mathrm{~mm}$ and outer diameter $4.4 \mathrm{~mm}, 3 \mathrm{M}$ Unitek, USA). The total surface area of one experimental elastomer was about $30.68 \mathrm{~mm}^{2}$. The mean mass was about $16.0 \mathrm{mg}$.

\section{Preparation of samples}

Eleven crowns of extracted molars were chosen as the experimental material. Each crown was cut into four or five blocks longitudinally with a low speed saw (Isomet, Buehler, Lake Bluff, Illinois, USA). Thirty-two enamel blocks, with no decalcification, crack or abrasion observable under $\times 4$ magnification (Mantis, Vinson Engineering Ltd. UK), were selected and polished with Merssage Brush (Shofu Co., Kyoto, Japan) and tap water. These enamel blocks were divided randomly into four groups respectively matching with the four kinds of fluoride concentration (Group1-1.25 wt\%, Group2-2.5 wt\%, Group3-3.75 wt\% and Group4-5.0 wt\%). In each group ( $n=8)$ an enamel block was cut into two smaller enamel blocks. The two blocks were prepared to a similar size with a water-cooled, high-speed handpiece. A $4 \times 2 \mathrm{~mm}$ window was designed at the center of the enamel surface. Each small enamel block was coated well with the acid-resistant varnish except the window. Because adjacent enamel blocks approximately have the same acid resistance, one of them was set with an experimental elastomer as test (E), the other as a control not set with the elastomer. Twenty-four plastic blocks (acryl) were prepared to be the same shape as the small enamel block and divided into four groups. Plastic blocks $(P, n=6)$ in 
each group were also set with the $1.25,2.5,3.75$ or $5.0 \mathrm{wt} \%$ experimental elastomers, respectively (Fig. 1).

\section{F'luoride release}

Each sample (E and $\mathrm{P}$ ) set with the elastomer was placed in a plastic vial containing $2 \mathrm{ml}$ de-ionized water and placed in a $37^{\circ} \mathrm{C}$ incubator for 10 days. The container and de-ionized water were changed every day and placed in the refrigerator at $4{ }^{\circ} \mathrm{C}$ until the measurement of the fluoride concentration. The measurement was done using ion meter and fluoride electrode (720A, Orion Research Inc, Boston, USA). Total ion strength adjustment buffer (TISAB III) was added at $10 \%(\mathrm{vol} / \mathrm{vol})$ to maintain a constant background ionic strength ${ }^{5)}$.

Observation of the fluoride distribution by EPMA

After fluoride release, five pairs of the enamel blocks set with $1.25 \mathrm{wt} \%$ elastomer and control were embedded in PMMA resin. The vertical cross surface was ground to a uniformly flat plane using no water. The electron probe microanalyser (EPMA, JXL-8900, JEOL Co. Tokyo) was used to detect the fluoride distribution in the enamel set with the elastomer and control. The color maps werc made in the condi-

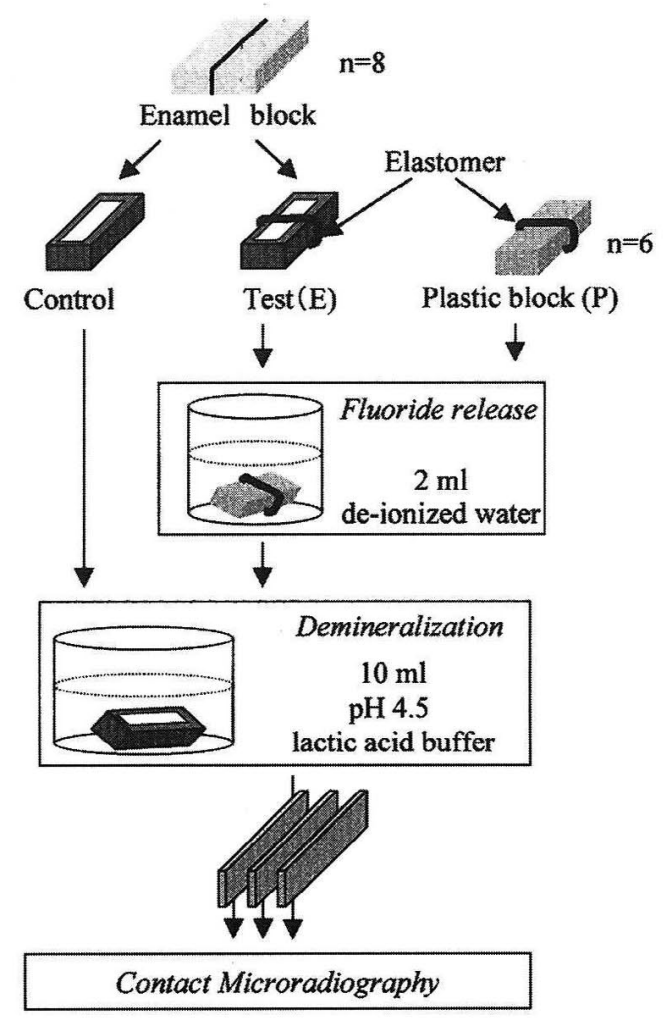

Fig. 1 The schematic experimental procedure. 
tions of $10 \mathrm{kv}$ accelerating voltage, $3 \times 10^{-8} \mathrm{~A}$ probe current and LDE1 analyzing crystal.

\section{Acid resistance}

After the fluoride release test, the elastomers were put out of the enamel blocks. Then each enamel block, including the test (E) and control, was placed in a plastic container with $10 \mathrm{ml}$ of $0.1 \mathrm{M}$ lactic acid buffer $(\mathrm{pH} 4.5)$, consisting of $0.1 \mathrm{M}$ lactic acid, $3.0 \mathrm{mM} \mathrm{Ca}, 1.8 \mathrm{mM} \mathrm{P}, 1 \%$ carboxymethylcellulose (CMC), $0.01 \%$ thymol $^{6)}$. The enamel blocks were artificially demineralized for 72 hours at $37^{\circ} \mathrm{C}$ with no vibration. Then the blocks were rinsed by de-ionized water to take off the residual buffer solution. The varnish on the enamel block was dissolved with acetone. After dried, the block was imbedded in Orthodontic Resin (Dentsply Caulk, DE, U.S.A.), sectioned into about $500 \mu \mathrm{m}$-thick sections with the low speed saw and ground into $100 \mu \mathrm{m}$-thick slices with waterproof abrasive paper (cc-800 1500 Riken Corundum, Japan) and rapping film (1 $\sim \mu \mathrm{m}$ Maruto Instrument Co, Tokyo, Japan). Finally each slice was cleaned ultrasonically for about 20 seconds.

\section{Contact Microradiography (CMR)}

To quantitatively determine the value of mineral loss in the demineralized enamel, a microradiograph was made by taking the slice together with an aluminum calibration step-wedge on high-resolution photographic film (SO343, Kodak Co. Tokyo, Japan) using a monochromatic X-ray generator (SPO-M, Sofron, Tokyo, Japan). The irradiation was processed in the condition of $15 \mathrm{kV}, 5 \mathrm{~mA}$ and 10 minutes, and the irradiation distance was $55 \mathrm{~mm}$. The radiographic density of the film was measured using a Microdensitometer (PDM-7, Konica, Tokyo, Japan) at the $2 \times 10 \mu \mathrm{m}$ slit. Nine scans were made in an enamel slice, as schematically shown in Fig. 2 . These data were processed through mineral density analysis (MDA) soft in computer and the plotted mineral tracings were subsequently assessed for mineral loss $(\Delta \mathrm{Z}$, vol\% . $\mu \mathrm{m})$.

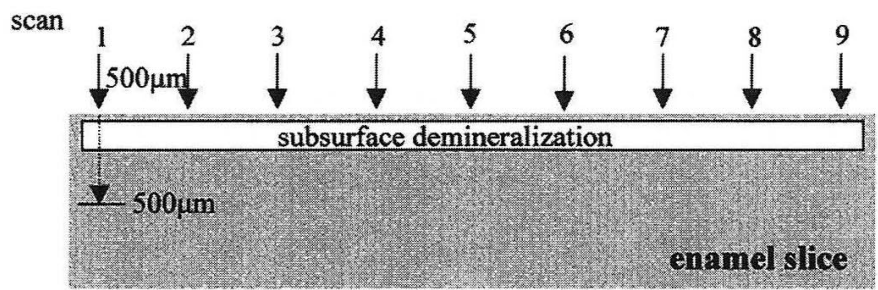

Fig. 2 Illustration of scans in an enamel slice by the microdensitometer.

Nine scans were processed in one slice. The average of the nine values of mineral loss was referred to as the mineral loss of onc slice. The average of two or three slices was referred to as the mineral loss of the small enamel block. 


\section{Data analysis}

The average of the values of mineral loss in nine sites of one slice was referred to as the mineral loss of each enamel slice. The mean value of the $2 \sim 3$ enamel slices in a same block was calculated out as the mineral loss of the small enamel block. The acquired acid resistance rate $(\mathrm{AR})$ of each enamel block was calculated by the following equation:

$\mathrm{AR}=\{(\Delta \mathrm{Zc}-\Delta \mathrm{Zt}) / \Delta \mathrm{Zc}\} \times 100 \%$

$\Delta \mathrm{Zt}$ : the mean mineral loss of one small enamel block as test.

$\Delta \mathrm{Zc}$ : the control.

\section{Statistical analysis}

The data were subjected to one-way analysis of variance (ANOVA) and the Scheffe's test at $\mathrm{p}<0.05$.

\section{RESULTS}

\section{Fluoride release}

Table 1 represents the daily concentration of the released fluoride ( $\mathrm{E}$ and $\mathrm{P}$ ) and the total fluoride concentration $(\Sigma)$ in the $2 \mathrm{ml}$ de-ionized water when the elastomer was set around the enamel or plastic block. It was shown that on the first day the rate

Table 1 Daily fluoride concentration $(\mathrm{ppm})$ in $2 \mathrm{ml}$ de-ionized water with enamel (E) or plastic (P) block

\begin{tabular}{|c|c|c|c|c|c|c|c|c|c|c|c|c|c|}
\hline \multirow{2}{*}{$\begin{array}{l}\mathrm{SnF}_{2} \\
(\mathrm{wt} \%)\end{array}$} & \multicolumn{11}{|c|}{ Time (day) } & \multirow{2}{*}{$\begin{array}{c}\text { Total } \\
(\Sigma)\end{array}$} & \multirow{2}{*}{$\begin{array}{l}\text { Absorbed } \\
\text { fluoride* }\end{array}$} \\
\hline & & 1 & 2 & 3 & 4 & 5 & 6 & 7 & 8 & 9 & 10 & & \\
\hline 1.25 & $\mathrm{P}$ & $\begin{array}{c}4.8 \\
(1.3) \\
4.4 \\
(0.5)\end{array}$ & $\begin{array}{c}2.1 \\
(0.9) \\
2.8 \\
(0.6)\end{array}$ & $\begin{array}{c}1.2 \\
(0.5) \\
2.8 \\
(2.1)\end{array}$ & $\begin{array}{c}0.9 \\
(0.3) \\
1.6 \\
(0.9)\end{array}$ & $\begin{array}{c}0.5 \\
(0.1) \\
0.9 \\
(0.1)\end{array}$ & $\begin{array}{c}0.6 \\
(0.2) \\
0.8 \\
(0.1)\end{array}$ & $\begin{array}{c}0.4 \\
(0.2) \\
0.6 \\
(0.1)\end{array}$ & $\begin{array}{c}0.4 \\
(0.2) \\
0.5 \\
(0.1)\end{array}$ & $\begin{array}{c}0.2 \\
(0.1) \\
0.4 \\
(0.0)\end{array}$ & $\begin{array}{c}0.3 \\
(0.1) \\
0.4 \\
(0.0)\end{array}$ & $\left.\begin{array}{c}11.3 \\
(1.7) \\
15.1 \\
(2.4)\end{array}\right]$ & $\begin{array}{c}3.8 \\
(1.1)\end{array} \pi$ \\
\hline 2.5 & $\begin{array}{l}\mathrm{E} \\
\mathrm{P}\end{array}$ & $\begin{array}{c}9.9 \\
(3.4) \\
10.5 \\
(1.6)\end{array}$ & $\begin{array}{c}4.6 \\
(2.3) \\
4.8 \\
(3.0)\end{array}$ & $\begin{array}{c}2.5 \\
(0.6) \\
4.2 \\
(1.0)\end{array}$ & $\begin{array}{c}1.9 \\
(0.8) \\
3.2 \\
(0.8)\end{array}$ & $\begin{array}{c}1.3 \\
(0.7) \\
2.6 \\
(0.8)\end{array}$ & $\begin{array}{c}1.8 \\
(1.1) \\
2.1 \\
(0.9)\end{array}$ & $\begin{array}{c}1.2 \\
(0.6) \\
1.8 \\
(0.8)\end{array}$ & $\begin{array}{c}1.1 \\
(0.5) \\
1.7 \\
(0.8)\end{array}$ & $\begin{array}{c}0.5 \\
(0.3) \\
1.4 \\
(0.7)\end{array}$ & $\begin{array}{c}0.9 \\
(0.4) \\
1.4 \\
(0.9)\end{array}$ & $\left.\begin{array}{c}25.6 \\
(4.5) \\
33.6\end{array}\right]$ & {$\left[\begin{array}{l}8.0 \\
(2.2)\end{array}\right]$} \\
\hline 3.75 & $\mathrm{E}$ & $\begin{array}{c}13.0 \\
(1.6) \\
16.1 \\
(3.4)\end{array}$ & $\begin{array}{c}4.8 \\
(0.6) \\
6.6 \\
(0.8)\end{array}$ & $\begin{array}{c}3.7 \\
(0.3) \\
5.6 \\
(0.8)\end{array}$ & $\begin{array}{c}3.4 \\
(0.3) \\
4.4 \\
(0.6)\end{array}$ & $\begin{array}{c}2.1 \\
(0.2) \\
3.7 \\
(0.4)\end{array}$ & $\begin{array}{c}2.9 \\
(0.2) \\
3.9 \\
(1.3)\end{array}$ & $\begin{array}{c}2.3 \\
(0.3) \\
2.9 \\
(0.4)\end{array}$ & $\begin{array}{c}2.2 \\
(0.4) \\
2.4 \\
(0.4)\end{array}$ & $\begin{array}{c}1.1 \\
(0.2) \\
1.9 \\
(0.3)\end{array}$ & $\begin{array}{c}1.7 \\
(0.3) \\
1.9 \\
(0.3)\end{array}$ & $\left.\begin{array}{c}37.1 \\
(1.9) \\
49.4\end{array}\right]$ & $\begin{array}{c}{[12.3} \\
(1.6)\end{array}$ \\
\hline 5.0 & $\begin{array}{l}\mathrm{E} \\
\mathrm{P}\end{array}$ & $\begin{array}{c}18.8 \\
(6.3) \\
26.9 \\
(2.5)\end{array}$ & $\begin{array}{c}6.5 \\
(1.3) \\
8.1 \\
(1.5)\end{array}$ & $\begin{array}{c}4.6 \\
(0.9) \\
5.7 \\
(0.9)\end{array}$ & $\begin{array}{c}3.8 \\
(0.5) \\
3.9 \\
(0.3)\end{array}$ & $\begin{array}{c}2.7 \\
(0.6) \\
3.3 \\
(0.3)\end{array}$ & $\begin{array}{c}3.6 \\
(0.5) \\
3.0 \\
(0.2)\end{array}$ & $\begin{array}{c}3.0 \\
(0.5) \\
2.6 \\
(0.2)\end{array}$ & $\begin{array}{c}3.2 \\
(0.5) \\
2.4 \\
(0.2)\end{array}$ & $\begin{array}{c}1.6 \\
(0.2) \\
2.1 \\
(0.1)\end{array}$ & $\begin{array}{c}2.5 \\
(0.3) \\
2.3 \\
(0.2)\end{array}$ & $\left.\begin{array}{c}50.2 \\
(6.6) \\
60.3\end{array}\right]$ & $\begin{array}{c}10.1 \\
(2.6)\end{array}$ \\
\hline
\end{tabular}




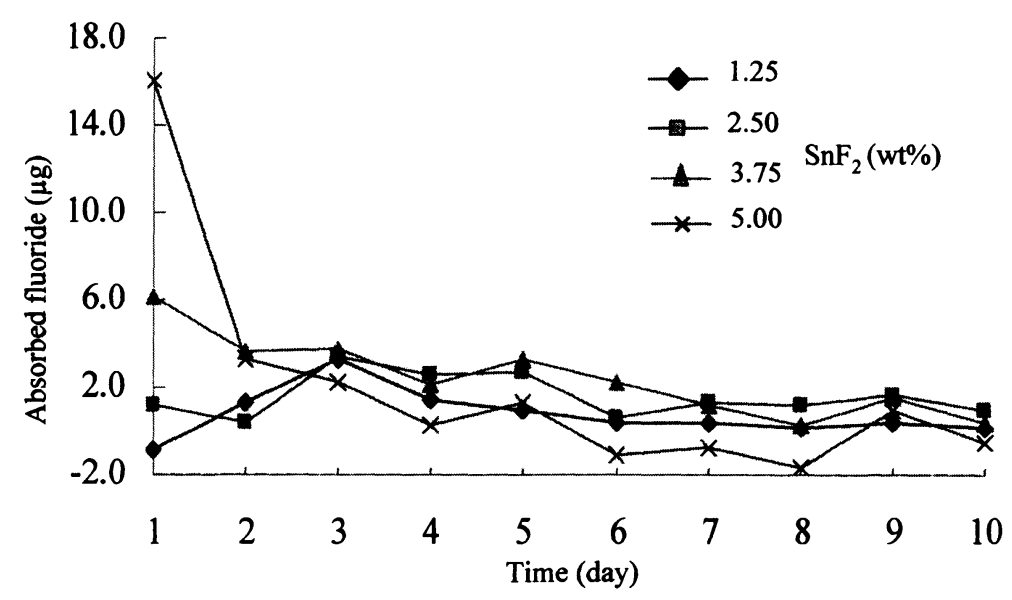

Fig. 3 The daily amount of fluoride absorbed by enamel.

The amount of absorbed fluoride was determined by the difference of the released fluoride by elastomers with plastic blocks and enamel blocks. The values showed that fluoride was largely absorbed on the first day, and with the immersion + time the absorbed fluoride became less and less.

of fluoride release was $2 \sim 3$ times of that on the second day. From the third day fluoride release was in the gradually decreasing state. When the fluoride-releasing elastomer was set with the enamel block (E), the total released fluoride was in the range of 11.3 to $50.2 \mathrm{ppm}$. On the other hand, when the fluoride-releasing elastomer was set with the plastic block $(\mathrm{P})$ the values were in the range of 15.1 to $60.3 \mathrm{ppm}$, greater than the former. Between them ( $\mathrm{E}$ and $\mathrm{P}$ ) the difference was statistically significant $(p<0.05)$ for all the four kinds of fluoride concentration.

\section{Absorbed fluoride}

As shown in Table 1, when the fluoride concentration was $1.25,2.5,3.75$ or $5.0 \mathrm{wt} \%$, the difference between the two kinds of fluoride release was $3.8,8.0,12.3$ or $10.1 \mathrm{ppm}$ respectively, which maybe resulted from the fluoride uptake of enamel. Fig. 3 longitudinally presents the daily absorbed fluoride by enamel during the immerse time. Only when the fluoride concentration was $5.0 \mathrm{wt} \%$ the sharp decline appeared from the first to the second day. For the other conditions, the curve appeared to be flat and gradually decreased to near zero.

\section{Observation of the fluoride distribution}

As shown in Fig. 4, EPMA maps showed the fluoride distribution in the enamel. The difference between the enamel affected by fluoride and the control may be detected by the color change in the surface of enamel. The yellow color in enamel of the former was apparently denser than in the latter. 


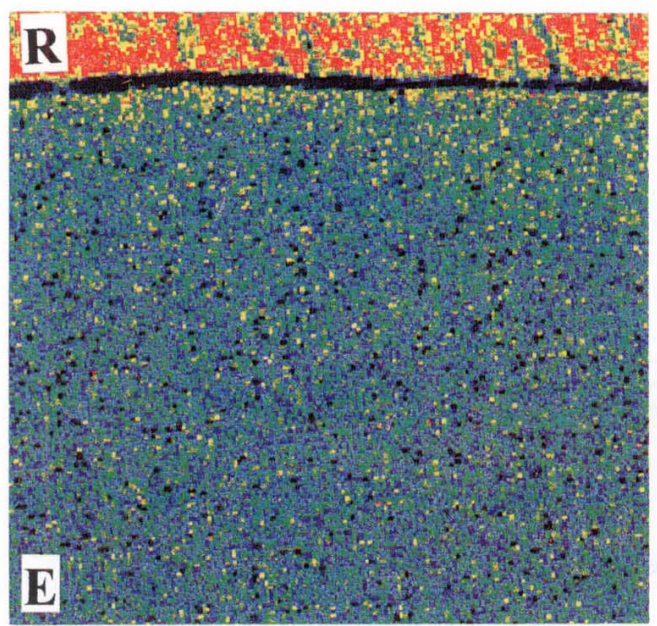

(1)

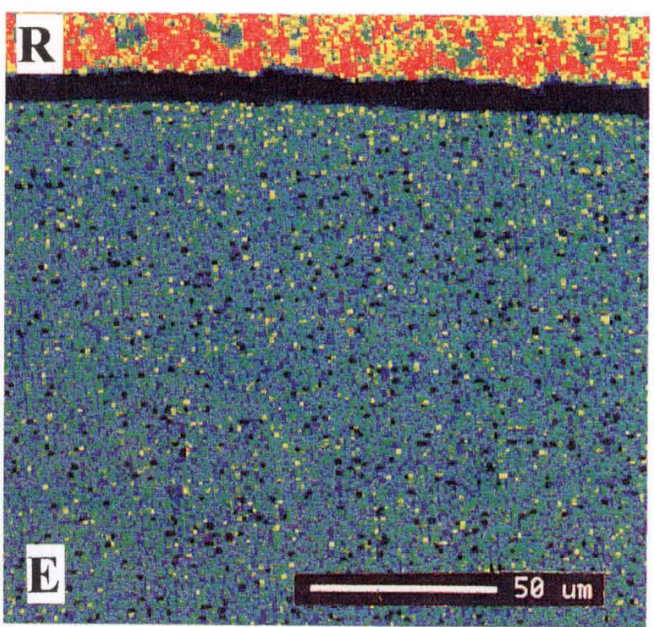

(2)

Fig. 4 Fluoride distribution analyzed by EPMA.

(1): the enamel affected by $1.25 \mathrm{wt} \%$ fluoride-releasing elastomers (2): the control $\mathrm{R}$ : embedding resin $\mathrm{E}$ : enamel

In the enamel surface, the yellow color (fluoride) was apparently denser than the control. Because of the trace of fluoride in the enamel, the measurement results were subjected to the influence of carbon in the embedding resin (red color).

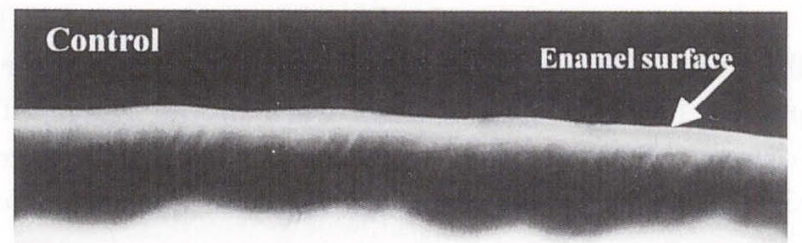

$100 \mu \mathrm{m}$

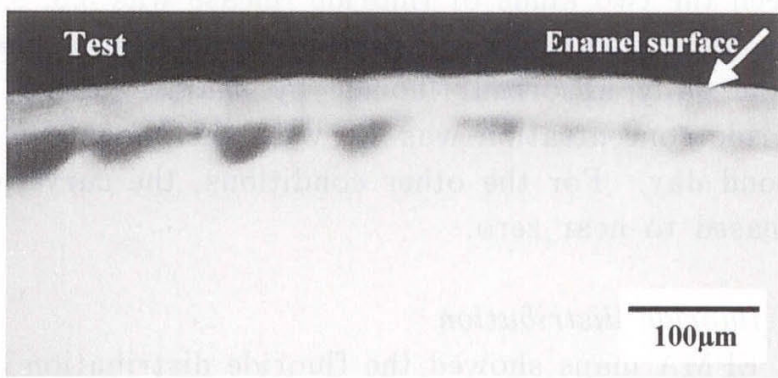

Fig. 5 CMR photographs.

The amount of mineral loss as well as lesion depth showed significant difference between the control and test $(1.25$ wt $\%$ fluoridereleasing elastomer). 
Table 2 The acquired acid resistance rate (AR)

$\left.\begin{array}{cl} & \multicolumn{1}{c}{\mathrm{n}=8} \\ \hline \mathrm{SnF}_{2}(\mathrm{wt} \%) & \overline{\mathrm{AR}}(\%) \\ \hline 1.25 & 52.7 \pm 12.2 \\ 2.5 & 54.3 \pm 13.7 \\ 3.75 & 60.5 \pm 9.5 \\ 5.0 & 70.0 \pm 11.6\end{array}\right]$

$\overline{\mathrm{AR}}$ : the average of 8 enamel block's AR

\section{Acid resistance and $C M R$}

Fig. 5 shows the photographs of the CMR. The demineralization degree (the area of darkness in the subsurface of enamel) of the enamel that had absorbed fluoride from the experimental elastomer apparently seemed to be smaller than that in the control. The acquired acid resistance rates (AR) of the enamel affected by the fluoridereleasing elastomers are shown in Table 2. When the fluoride concentration of the elastomer was $1.25,2.5,3.75$, or $5.0 \mathrm{wt} \%$, AR was about $53,54,61$, or $70 \%$ respectively. Although with the increase of fluoride concentration in the elastomers the acid resistance of enamel seemed to become larger, only between group 1 (1.25 wt\%) and group $4(5.0 \mathrm{wt} \%)$ AR was significantly different $(\mathrm{p}<0.05)$.

\section{DISCUSSION}

Because in vivo dynamic changes in temperature, $\mathrm{pH}$, salivary and bacterial enzymes will contribute to a more rapid decay in the properties of the elastomers, in vitro the simulated oral environment maybe underestimate the loss of material properties ${ }^{7)}$. Therfore, the fluoride release rate of the experimental elastomers in vitro only grossly indicated the fluoride release ability of the elastomers when set in the oral cavity. Actually, in vitro fluoride release rate may be overestimated compared to that in vivo ${ }^{8)}$. In the study, the experimental elastomers showed the ability to release enough fluoride to reduce demineralization. On the tenth day, the lowest fluoride concentration was about $0.3 \mathrm{ppm}$, which was much higher than $0.05 \mathrm{ppm}$. It was reported that fluoride concentration no less than $0.05 \mathrm{ppm}$ would be beneficial for demineralization inhibition $^{9}$. Furthermore, since in the oral cavity the fluoride ion may be diffused into saliva and ingested, to more effectively inhibit the demineralization the maintenance of some low fluoride concentration is of great importance, which accounted for studies on the fluoride-releasing materials.

In this study during the experimental period (10 days) the elastomer released only about $15 \%$ of the total fluoride in the elastomer, which showed that the elastomers had the potential to release fluoride constantly for a longer time. The total amount of released fluoride appeared to become significantly greater with the increase of fluoride concentration in the elastomer, when set with an enamel or plastic block. This property was similar to the fluoride-releasing glass-ionomers that 
Creanor et $a l^{10)}$ reported; fluoride-releasing glass-ionomers with a high concentration of fluoride would be expected to release more fluoride than ones with a lower concentration. On the other hand, the pattern of fluoride-release from the experimental elastomers was characterized by an initial burst of fluoride released during the first day. The amount of released fluoride on the first day was about $2 \sim 3$ times that on the second day. From the second day, the fluoride release became slow and relatively stable. This property was similar to that of other fluoride-releasing materials $^{11,12)}$.

Indeed the amount of fluoride released from the experimental fluoride-releasing elastomers comprised of the fluoride in the de-ionized water and the fluoride that was absorbed by the enamel, so the fluoride release was performed when the elastomer was not only set with the enamel block, but also set with the plastic block (control) in the study. This was different from the previous studies ${ }^{13,14}$ in that the fluoride release from the fluoride-releasing elastomers (Fluor-I-Ties or Fluor-IChains) was not carried out together with the enamel in vitro. From the variation of the released fluoride in these two different conditions, the fluoride absorbed by the enamel may be calculated grossly. Although the amount of fluoride absorbed by enamel increased from $3.8 \mathrm{ppm}$ to $12.1 \mathrm{ppm}$ with increasing the fluoride concentration in elastomers from 1.25 to $5.0 \mathrm{wt} \%$, the difference of the absorbed fluoride became less when the fluoride concentration became greater, which indicated that the fluoride uptake was in the saturated state.

Clinically, to prevent the demineralization and enhance the remineralization, fluoride has been used in many modalities, such as mouth rinse, topical fluoride treatment and the use of fluoride-releasing materials. When the fluoride concentration is higher than $4 \mathrm{mmol} / \mathrm{L}(76 \mathrm{ppm})$ in the fluoride solution, the major effect of fluoride is mainly due to calcium fluoride $\left(\mathrm{CaF}_{2}\right)$ formation on the enamel surface or in lesions, which means the dissolution of a very thin layer of enamel and concomitant precipitation of calcium fluoride ${ }^{15-17)}$. In this experiment the fluoride concentration may be too high around the enamel contacting with the fluoride-releasing elastomer to make $\mathrm{CaF}_{2}$ formed, as pointed in the previous paper ${ }^{4)}$. Whilst in the condition of low fluoride concentration (less than $76 \mathrm{ppm}$ ) the formation of fluorapatite (FAP) plays an important role of inhibiting demineralization ${ }^{14,17}$. In this study, the fluoride concentration in the de-ionized water was in the range of 0.3-26.9 ppm, which may be promoted to form FAP in the surface enamel. Although the value of the absorbed fluoride was $3.75 \mathrm{wt} \%$, there was no significant difference with $5.0 \mathrm{wt} \%$. It was possible that the formation of $\mathrm{CaF}_{2}$ and FAP became saturated. And because the enhancement of acid resistance was contributed to the combination of $\mathrm{CaF}_{2}$ and FAP formations, the change of $\mathrm{AR}$ was not only decided by the amount of absorbed fluoride, but also the composition of the fluoride compound. Because in the study the composition of the formed fluoride compound had not been investigated, it was not clear why AR showed no significant difference although the absorbed fluoride for $1.25 \mathrm{wt} \%$ was less than for $2.5 \mathrm{wt} \%$. AR showed the tendency to increase with fluoride concentration, but the differences among them were not significant. Only when 
fluoride concentration in the elastomers was 1.25 and 5.0 wt\% did AR between them show a statistically significant difference. In a word, the acquired acid resistance of enamel was not proportional to the amount of fluoride in the experimental elastomers. This agrees with the report on some fluoride-releasing composites, that at higher fluoride content, the reduction in demineralization appears to be independent of the fluoride level ${ }^{18)}$.

Although in some extent the increase of fluoride concentration is beneficial to fluoride incorporation into enamel the optimal level of fluoride is still unknown ${ }^{19)}$. For fluoride-releasing elastomers, the determination of the most suitable fluoride concentration would be complicated. The optimal fluoride concentration in the elastomers must comprehensively be determined by combining the potential to enhance the acid resistance of enamel with the influence of fluoride on the mechanical properties of the elastomers. In further studies, it is necessary to investigate the influence of fluoride on the mechanical properties of elastomers.

\section{CONCLUSION}

1. The amount of fluoride released from the experimental elastomers increased with the increase of fluoride concentration of the elastomers $(1.25<2.5<3.75<5.0 \mathrm{wt} \%)$.

2 . The acquired acid resistance of human enamel did not increase proportionally with the increase of fluoride concentration in the experimental elastomers.

\section{REFERENCES}

1) Storie, D. J., Regennitter, F. and von Fraunhofer, J.A.: Characteristics of a fluoridereleasing elastomeric chain, Angle Orthod 64(3): 199-210, 1994.

2) Banks, P. A., Chadwick, S. M., Asher-Mcdade, C. and Wright, J. L.: Fluoride-releasing elastomerics - a prospective controlled clinical trial-, Europ $J$ Orthod $22: 401-407,2000$.

3) Itoh, Y.: The study of fluoride-releasing rubber for separation of teeth, Jpn J Ped Dent 38 (3) : 562-575, 2000. (in Japanese)

4) Wang, X. Y., Miyazaki, K., Itoh, Y. and Motokawa, W.: Effect of experimental fluoridereleasing tooth separator on acid resistance of human enamel in vitro, Dent Mater $J$ 20(4) : 275-285, 2001.

5) Suljak, J. P. and Hatibovic-Kofman, S.: A fluoride release-adsorption-release system applied to fluoride-releasing restorative materials, Quintessence Int $27: 635-638,1996$.

6) Yu, H. L., Iijima, Y. and Kawasaki, K.: An acid resistance test after remineralization of enamel in vitro - The influence of an equal ratio of demineralization and remineralization periods-, J Dent Hlth 48 : 697-706, 1998.

7) Boyd, R. and Kaplia, S.: Commentary: fluoride-releasing elastomeric chains, Angle Orthod $64: 210,1994$.

8) Wiltshire, W. A.: In vitro and in vivo fluoride releasse from orthodontic elastomeric ligature ties, Am J Orthod Dentofacial Orthop 115 : 288-292, 1999.

9) Ten Cate, J. M. and Duijsters, P. P. E.: Influence of fluoride in solution on tooth demineralization. 1. Chemical data, Caries Res $17: 193-197,1983$.

10) Creanor, S. L., Carruthers, L. M. C., Saunders, W. P. Strang, R. and Foye, R. H.: Fluoride uptake and release characteristics of glass ionomer cements, Caries Res 28:322328, 1994.

11) Eichmiller, F.C. and Marjenhoff, W. A.: Fluoride-releasing dental restorative materials, 
Operative Dent 23 : 218-228, 1998.

12) Chan, D. C. N., Swift, E. J. and Bishara, S. E.: In vitro evaluation of a fluoride-releasing orthodontic resin, $J$ Den Res 69 : 1576-1579, 1990.

13) Joseph, V.P., Grobler, S. R. and Rossouw, P. E.: Fluoride release from orthodontic elastic chain, $J$ Clin Orthod 27 : 101-105, 1993.

14) Wiltshire, W. A.: Determination of fluoride from fluoride-releasing elastomeric ligature ties, Am J Orthod Dentofac Orthop $110: 383-387,1996$.

15) Rølla, G. and Saxegaard, E.: Critical Evaluation of the coposition and use of topical fluorides, with emphasis on the role of calcium fluoride in caries inhibition, $J$ Dent Res 69 (Spec Iss) : 780-785, 1990.

16) Caslavska, V., Moreno, E. C. and Brudevold, F.: Determination of the calcium fluoride formed from in vitro exposure of human enamel to fluoride solutions, Archs oral Biol $20: 333-339,1975$.

17) Dawes, C. and Weatherell, J. A.: Kinetics of fluoride in the oral fluids, $J$ Dent Res 69 (Spec Iss) : 638-644, 1990.

18) Dijkman, G. E. H. M. and Arends, J.: Secondary caries in situ around fluoride-releasing light-curing compsites: A quantitative model investigation on four materials with a fluoride content between 0 and 26 vol\%, Caries Res 26:351-357, 1992.

19) Chadwick, S. M. and Gordon, P. H.: An investigation to estimate the fluoride uptake adjacent to a fluoride-releasing bonding agent, Brit J Orthod 22 :113-122, 1995. 